J. Clin. Chem. Clin. Biochem.

Vol. 26, 1988, pp. 219-222

(C) 1988 Walter de Gruyter \& Co. Berlin - New York

\title{
Plasma Haemoglobin Determination Using Chlorpromazine as a Non-Carcinogenic Reagent
}

\author{
By Kristiina Nyyssönen, M. T. Parviainen and I. M. Penttilä \\ Department of Clinical Chemistry, Kuopio University Central Hospital, Kuopio, Finland
}

(Received March 26/August 21, 1987/January 18, 1988)

Summary: Plasma haemoglobin was assayed with the non-carcinogenic reagent phenothiazine. This method is sensitive and allows the measurement of plasma haemoglobin concentrations in the range $4-500 \mathrm{mg} / \mathrm{l}$ with a within-run CV of $2.1 \%$, and a between-run CV of $4.3 \%$. A spectrophotometric scanning method (x) based on the determination of haemoglobin as haemiglobin cyanide using the Soret band at $419 \mathrm{~nm}$ correlated well with the phenothiazine method $(y): y=1.07 x+15.8, r=0.995, n=31$. It was found that the absorbances in the phenothiazine method were markedly dependent on the concentration of phosphoric acid.

\section{Introduction}

The quantitative determination of plasma haemoglobin is of clinical importance in haemolytic disorders, which occur either in vivo $(1,2)$ or in vitro (3). However, the carcinogenity of many commonly used reagents is undesirable for routine laboratories. Benzidine, $o$-tolidine (4) and dicarboxidine (5), used in previous studies, are all carcinogens. Of the suggested alternative non-carcinogenic chromogens, tetramethylbenzidine $(6,7)$ aminophenazone $(8)$, and $2,2^{\prime}-$ azino-di-(3-ethylbenzthiazoline-6-sulphonic acid) (ABTS) $(9,10)$ have proved suitable for the quantitative determination of plasma haemoglobin. The reaction of these materials with haemoglobin is based on the peroxidase activity of the haemoprotein. Spectrophotometric scanning techniques do not require carcinogenic reagents $(11,12,13)$, but are only accessible to those laboratories possessing scanining equipment.

Recently, Ferencz \& Bacso (14) developed a method for the determination of haemoglobin in plasma or serum using phenothiazines. This method is also based on the peroxidase activity of haemoglobin, but the main reason for recommending this reagent is its noncarcinogenity. They also introduced the use of phosphoric acid to stabilize the coloured reaction end product. We have evaluated a modification of the method using chlorpromazine and found it sufficiently rapid and sensitive to measure plasma haemoglobin concentrations of $4-500 \mathrm{mg} / \mathrm{l}$.

\section{Materials and Methods}

Glacial acetic acid, phosphoric acid and $\mathrm{Na}_{2}$ EDTA were from E. Merck (Darmstadt, F. R. G.). Chlorpromazine $(250 \mathrm{mg})(\mathrm{Ph}$. Nord., Yliopiston Apteekki, Helsinki, Finland) was dissolved in $100 \mathrm{ml}$ of $5.4 \mathrm{mmol} / 1 \mathrm{Na}_{2}$ EDTA. This solution is stable for one week at $+4^{\circ} \mathrm{C}$. Phosphoric acid was diluted to $5 \mathrm{~mol} / \mathrm{l}$ with distilled water. Hydrogen peroxide (Bang \& Co., Helsinki, Finland) solution was freshly prepared daily from $300 \mathrm{~g} / \mathrm{kg}$ $\mathrm{H}_{2} \mathrm{O}_{2}$ by diluting $3.4 \mathrm{ml}$ of $\mathrm{H}_{2} \mathrm{O}_{2}$ in $100 \mathrm{ml}$ of distilled water. All reagents were of "pro analysis" quality. A $300 \mu$ l aliquot of whole blood, whose haemoglobin concentration had previously been determined by Coulter Counter ${ }^{\circledR}$ S-PLUS IV (Coulter Electronics, Inc., Hialcah, U.S.A.) using the haemiglobin cyanide technique checked by Coulter quality control $4 \mathrm{c}$, was haemolyzed by diluting to $100 \mathrm{ml}$ with water. This solution was used as a haemoglobin standard and is stable at $20^{\circ} \mathrm{C}$ for at least 6 months. Patient plasma samples were collected using either sodium heparin or potassium EDTA tubes (Venoject, Terumo Corp., Tokyo, Japan) which are used routinely in our laboratory.

To $20 \mu$ l of plasma or standard we added $0.5 \mathrm{ml}$ of chlorpromazine solution, $1.4 \mathrm{ml}$ acetic acid and $0.2 \mathrm{ml}$ of $5 \mathrm{~mol} / 1 \mathrm{H}_{3} \mathrm{PO}_{4}$. Reaction was started by adding $1.0 \mathrm{ml}$ of $\mathrm{H}_{2} \mathrm{O}_{2}$. The final concentrations of the reagents of the assay mixture were:

chlorpromazine $0.4 \mathrm{~g} / \mathrm{l}$,

acetic acid $7.9 \mathrm{~mol} / \mathrm{l}$,

$\mathrm{H}_{3} \mathrm{PO}_{4} 0.32 \mathrm{~mol} / 1$ and

$\mathrm{H}_{2} \mathrm{O}_{2} 0.09 \mathrm{~mol} / \mathrm{l}$. 
The absorbance was measured against a blank which had been prepared using pooled haemoglobin-free plasma. The absorbance readings at $528 \mathrm{~nm}$ (Zeiss PM 2 DL Spektrophotometer, Zeiss, Oberkochen, F. R. G.) were recorded exactly eight minutes after the addition of the $\mathrm{H}_{2} \mathrm{O}_{2}$ solution.

The haemoglobin-frec plasma used as a blank was checked by measuring the absorbance of the reaction against the reaction of the sample replaced by water. This blank absorbance reading was not allowed to exceed 0.07 .

The effects of bilirubin and ascorbic acid on the assay were studied. Bilirubin (Fluka AG, Buchs, Switzerland) $100 \mathrm{mg}$, was dissolved in $0.1 \mathrm{~mol} / \mathrm{l} \mathrm{NaOH}$ and diluted to $20 \mathrm{ml}$ with $50 \mathrm{~g} / 1$ of bovine albumin solution (Sigma, St. Louis, USA). Ascorbic acid (Merck) $200 \mathrm{mg}$ was dissolved in $100 \mathrm{ml}$ of water. These stock solutions were added to pooled plasma.

\section{Results and Discussion}

The linearity of the method was checked by making a series of dilutions of the standard in water and analysing as described. To confirm the standardisation of the method we used a haemoglobin control from Merz + Dade AG (Duedingen, Switzerland, haemoglobin concentration $110 \mathrm{~g} / \mathrm{l})$. The control was diluted and used in the same way as the standard. Figure 1 shows the results obtained using dilutions of the standard and the control.

The within-run coefficient of variation (CV) was $2.1 \%$ $(\mathrm{n}=10)$ using a patient sample containing $362 \mathrm{mg} / \mathrm{l}$ haemoglobin. The between run $\mathrm{CV}$ was $4.3 \%$ ( $\mathrm{n}=10$, sample containing $251 \mathrm{mg} / \mathrm{l}$ haemoglobin). The analyses for determining the between run variation were performed during a seven-week period.

It was found that a final concentration of $0.4 \mathrm{~g} / 1$ chlorpromazine in the assay mixture was sufficient, provided the chlorpromazine solution was freshly prepared. Higher concentrations of chlorpromazine led to absorbance readings that were too high for measurement with the spectrophotometer at the plasma haemoglobin level of $430 \mathrm{mg} / \mathrm{l}$ and above. During storage the chlorpromazine solution slightly looses its capacity to be peroxidized by hydrogen peroxide, and the intensity of the coloured end product as well as the linearity of the method are decreased.

The concentration of phosphoric acid in the reaction mixture was of critical importance. The absorbance of the reaction end product was found to increase as the concentration of the phosphate increased (fig. 2). However, the absorbance maximum was reached later in higher phosphate concentrations and the colour was more unstable (fig. 2). Ferencz \& Bacso (14) used the final concentration of $0.16 \mathrm{~mol} / 1 \mathrm{H}_{3} \mathrm{PO}_{4}$ in the assay mixture to stabilize the colour of the end product. However we found that $0.16 \mathrm{~mol} / \mathrm{l}$ instead of 0.32 $\mathrm{mol} / 1 \mathrm{H}_{3} \mathrm{PO}_{4}$ in the reaction mixture caused a dramatic

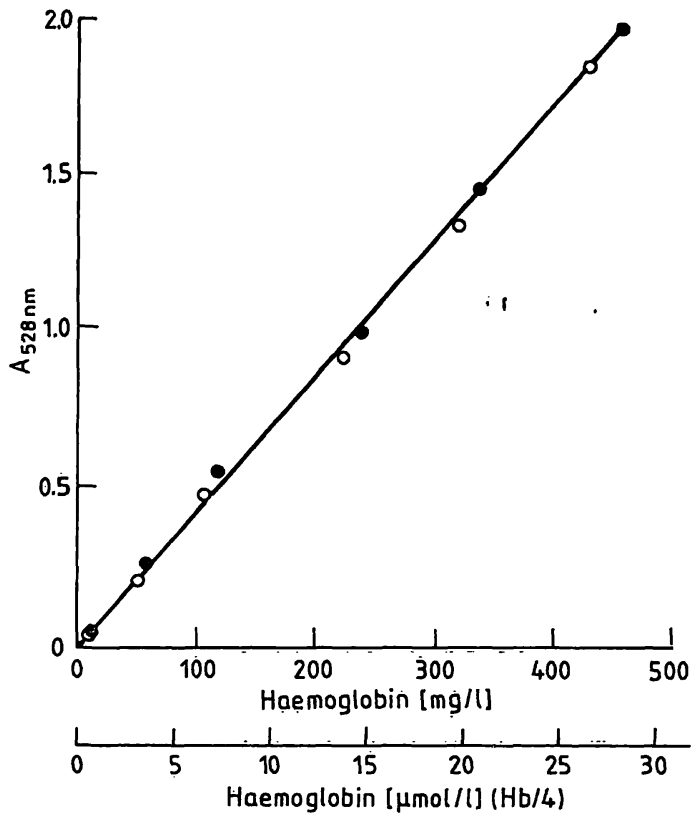

Fig. 1. Linearity of absorbance readings against haemoglobin concentration;

$(\bullet),(0)$ represent dilutions of the standard and control, respectively.

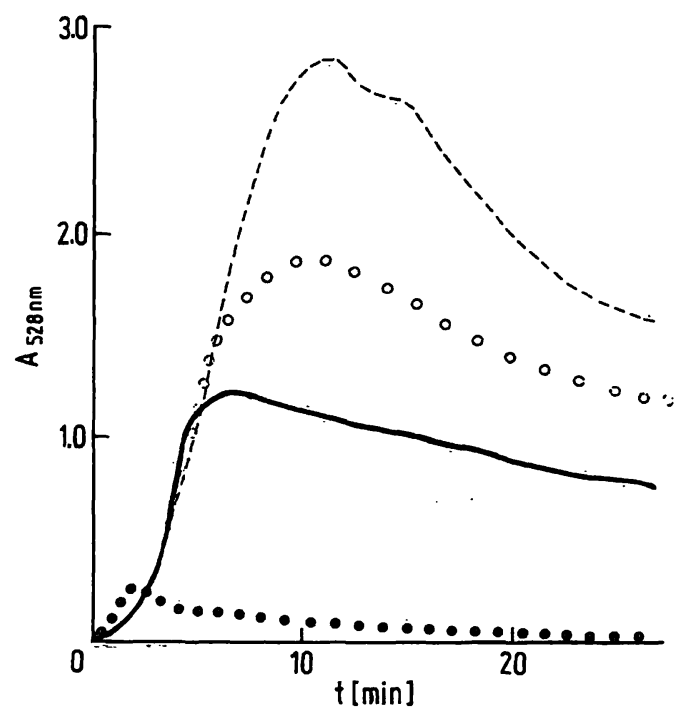

Fig. 2. Effect of the concentration of $\mathrm{H}_{3} \mathrm{PO}_{4}$ on the colour development in the reaction mixture (chlorpromazine $0.4 \mathrm{~g} / \mathrm{l}$, glacial acetic acid $7.9 \mathrm{~mol} / 1, \mathrm{H}_{2} \mathrm{O}_{2} 0.09 \mathrm{~mol} / 1$ and $20 \mu \mathrm{l}$ of a sample with $380 \mathrm{mg} / \mathrm{l}$ of haemoglobin); (๑००) without $\mathrm{H}_{3} \mathrm{PO}_{4}$,

$(\longrightarrow) 0.32 \mathrm{~mol} / 1 \mathrm{H}_{3} \mathrm{PO}_{4}$,

(০o) $0.64 \mathrm{~mol} / 1 \mathrm{H}_{3} \mathrm{PO}_{4}$,

(-- -) $0.95 \mathrm{~mol} / 1 \mathrm{H}_{3} \mathrm{PO}_{4}$.

The absorbance readings were taken at a 30 seconds interval.

reduction in the absorbance values, and the linearity of the method decreased (fig. 3). A final concentration of $0.32 \mathrm{~mol} / 1 \mathrm{H}_{3} \mathrm{PO}_{4}$ proved to be the optimal with respect to absorbance and stability for plasma haemoglobin concentrations of $4-500 \mathrm{mg} / \mathrm{l}$. Samples with haemoglobin concentrations above $500 \mathrm{mg} / \mathrm{l}$ weré diluted $1: 5$ with $9 \mathrm{~g} / 1 \mathrm{NaCl}$. 


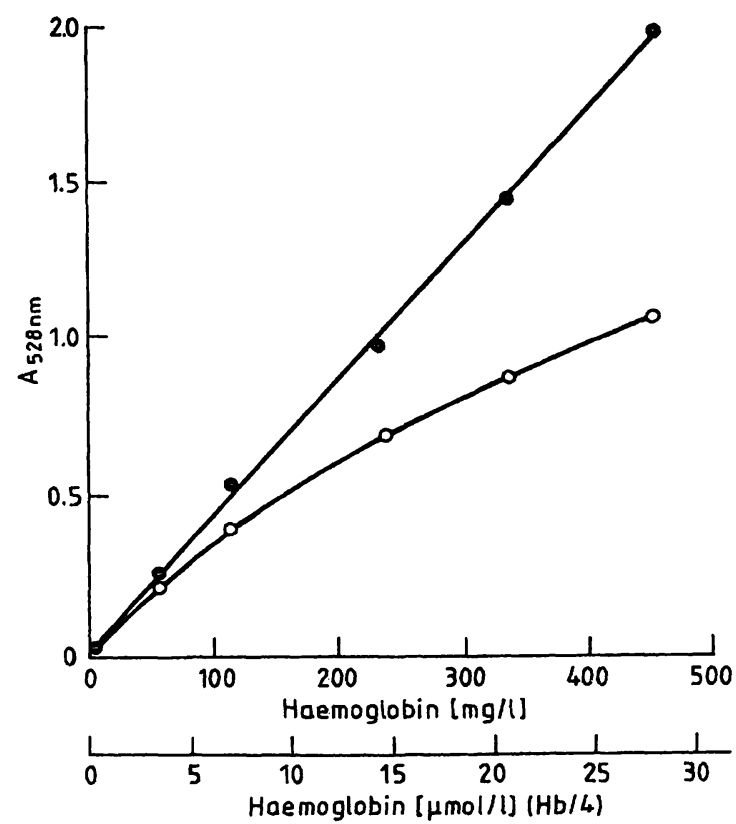

Fig. 3. Effect of the concentration of $\mathrm{H}_{3} \mathrm{PO}_{4}$ in the reaction mixture.

$(0),(0)$ represent the absorbances against concentration when the reaction mixture contained $0.32 \mathrm{~mol} / \mathrm{l}$ or 0.16 $\mathrm{mol} / 1 \mathrm{H}_{3} \mathrm{PO}_{4}$, respectively.

The detection limit of the assay was $4 \mathrm{mg} / \mathrm{l}$ which corresponds to an absorbance reading of 0.01 at 528 $\mathrm{nm}$. The normal range for plasma haemoglobin is usually given as $0-25 \mathrm{mg} / 1(4,7)$ or $0-50 \mathrm{mg} / \mathrm{l}$ $(8,10)$.

The chlorpromazine method described (y) was compared with the spectrophotometric scanning method (x) based on the determination of haemoglobin as haemiglobin cyanide using the Soret band at $419 \mathrm{~nm}$ (4). A linear regression equation for the two methods was $y=1.07 x+15.8$ (31 patient samples), with haemoglobin concentrations between $0-1148 \mathrm{mg} / 1$ $(\mathrm{r}=0.995$, fig. 4). The chlorpromazine method gave slightly higher results (paired t-test $\mathrm{p}<0.001$ ).

Lipaemic samples may cause erroneously high results. For turbid samples we prepared sample blanks: $20 \mu \mathrm{l}$ of the sample was first treated with $1 \mathrm{ml}$ of $\mathrm{H}_{2} \mathrm{O}_{2}$ for 10 minutes, followed by addition of other reagents.

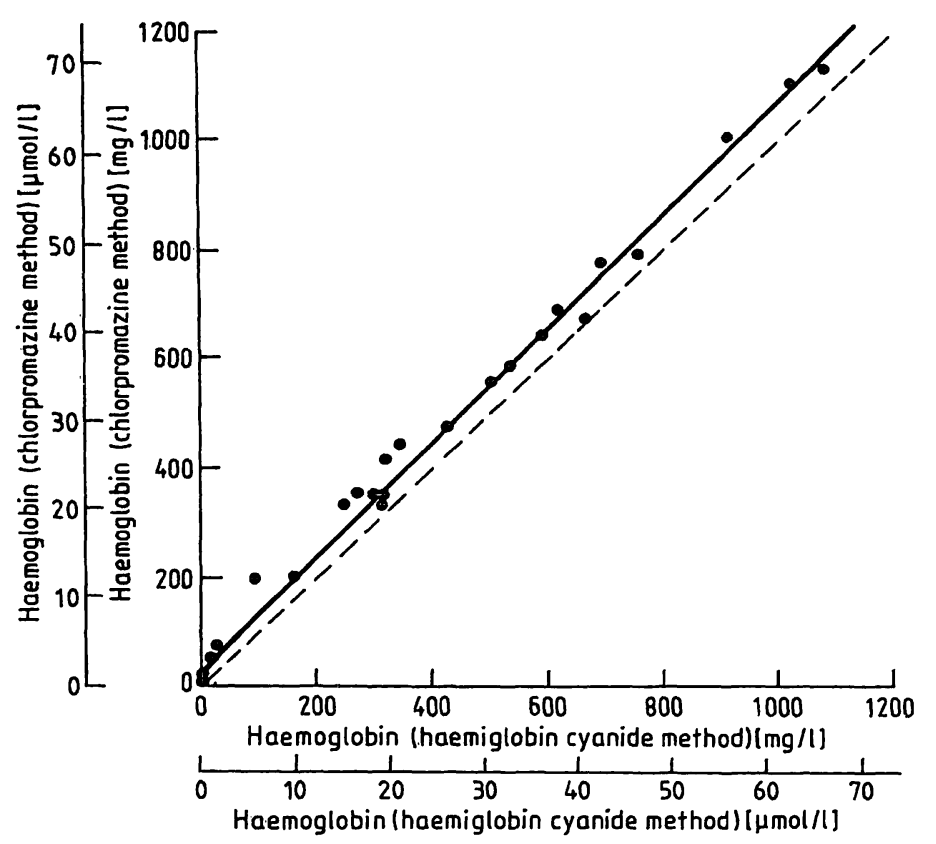

Fig. 4. Comparison of results observed using the chlorpromazine and haemiglobin cyanide method, dotted line: $\mathbf{y}=\mathbf{x}$.

Cf. text for details.

Previous studies have demonstrated that the anticoagulants oxalate, citrate, EDTA and heparin have no effect on the phenothiazine methods. Ascorbic acid in high concentration does inhibit the colour development of both the phenothiazine and the benzidine method in plasma and in urine $(14,15)$. We tested the effect of ascorbic acid and bilirubin on the chlorpromazine method. Ascorbic acid was added to plasma to give final concentrations of $32,56,111$ and $222 \mu \mathrm{mol} / \mathrm{l}$; and bilirubin was added to plasma to give concentrations of $40,80,160$ and $388 \mu \mathrm{mol} / 1$ with a haemoglobin concentration of $636 \mathrm{mg} / \mathrm{l}$. Analytical recoveries of haemoglobin in these samples were $96 \%-100 \%$ for plasma spiked with ascorbic acid and $102 \%-109 \%$ for plasma spiked with bilirubin. We conclude that neither ascorbic acid nor bilirubin at their physiological or elevated concentrations have any marked effect on this method.

\section{References}

1. Dacie, J. (1985) In: The Haemolytic Anemias, The Hereditary Haemolytic Anaemias, Part 1, Churchill Livingstone, Edinburgh, pp. 7-63.

2. Blank, D. W., Kroll, M. H., Ruddel, M. E. \& Elin, R. J. (1985) Clin. Chem. 31, 1566-1569.

3. Guder, W. G. (1986) J. Clin. Chem. Clin. Biochem. 24, 125-126.

4. Fairbanks, V. F. (1976) In: Fundamentals of Clinical Chemistry (Tiez, N. W., ed.) W. B. Sounders Company, Philadelphia, pp. $401-454$.

5. Sw̌olin, B., Roberts, D. \& Waldenström, J. (1982) Clin. Chim. Acta 121, 389-391.

6. Standefer, J. C. \& Vanderjagt, D. (1977) Clin. Chem. 23, $749-751$.

7. Lewinson, S. S. \& Goldman, J. (1982) Clin. Chem. 28, $471-474$.

8. Bauer, K. (1981) J. Clin. Chem. Clin. Biochem. 19, 971 976.

9. Marklund, S. (1978) Scand. J. Clin. Lab. Invest. 38, 543547. 
10. Takayanagi, M. \& Yashiro, T. (1984) Clin. Chem. 30, 357359.

11. Harboe, M. (1959) Scand. J. Clin. Lab. Invest. 11, 66-70.

12. Kahn, S. E., Watkins, B. F. \& Bermes, E. W. (1981) Ann. Clin. Lab. Sci. 11, 126-131.
13. Merrick, M. F. \& Pardue, H. L. (1986) Clin. Chem. 32, $598-602$.

14. Ferencz, A. \& Bacso, M. (1983) Clin. Chim. Acta 134, $103-106$.

15. Ahmed, S. A. \& Gowda, S. H. (1981) Clin. Chem. 27, 1309-1310.

M. T. Parviainen, Ph. D.

Department of Clinical Chemistry

Kuopio University Central Hospital

SF-70210 Kuopio 